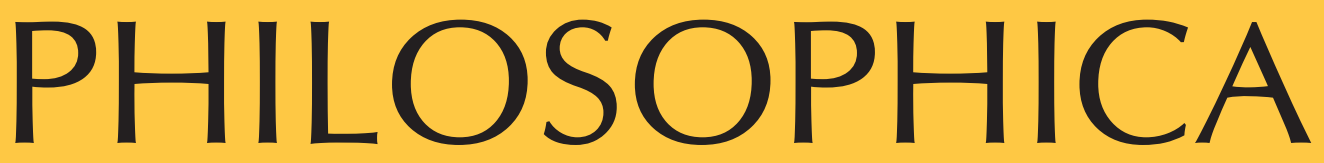

\author{
FILOSOFIA E MEDICINA \\ SOBRE DOR E SOFRIMENTO
}

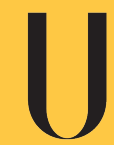

$$
\begin{gathered}
\text { LISBDA } \\
\text { UNIVERSIDADE } \\
\text { DE IISBOA }
\end{gathered}
$$

Departamento de Filosofia

Faculdade de Letras da Universidade de Lisboa Centro de Filosofia da Universidade de Lisboa 


\title{
A Propósito da Naturalização da Dor na Obra de Filipe Montalto
}

\author{
Manuel Silvério Marques ${ }^{1}$ \\ (Médico Aposentado, Centro de Filosofia da Universidade de Lisboa) \\ José Morgado Pereira ${ }^{2}$ \\ (Psiquiatra, CEIS20, Universidade de Coimbra)
}

"As imagens do mundo interno são aquelas que descrevemos em termos de bemestar, fadiga, ou desconforto; dor ou prazer; palpitações, azia, cólicas (...). Estas imagens do mundo interno_antigo_são os componentes nucleares dos sentimentos."

António Damásio, A estranha ordem das coisas, 2017, pp. 118-119.

\section{Introdução}

A experiência da dor e do penar, o discurso da perda e do dó gravita em torno de dois pólos, um pólo negativo do inefável e incomunicável, genialmente introduzido por Borges em Tlön e o pólo positivo da reacção de revolta hiperbólica, que Camus entronizou em $O$ Homem Revoltado. Existe sempre um pudor natural em falar das nossas misérias, das próprias doenças, das falhas e pecados cometidos mas, estranhamente, também sentimos vergonha, acanhamento e até culpa no acto de conversar casualmente acerca dos padecimentos e das dores de outrem - sobretudo quando se trata de alguém que nos toca, está perto ou nos pede auxílio e... nós nos sabemos impotentes e nos sentimos limitados a ser meros espectadores. Ainda assim, a medicina, com a sua origem meio mágica,

1 m.marques46@gmail.com

2 jmorgadopereira@gmail.com

Philosophica, 52, Lisboa, 2018, pp. 43-57. 
meio empírica, arranjou sempre a boa justificação: tentar ajudar a combater a doença e a minorar a dor, medidas prudenciais, mesmo quando os métodos requeridos pela Arte eram cruentos e cruéis.

Mas na presença do sofrimento intenso, desumano, intolerável, inenarrável de um doente, de um inocente - do próximo - para lá da espontânea compaixão e empatia, são previsíveis também reacções extremas - ocultas ou manifestas - do medo à revolta, do grito ao desespero. Mas há que reconhecer que os discursos "técnicos" e as narrativas escolares sobre a dor (como ocorre ainda nos manuais das doenças) incorrem não poucas vezes num distanciamento inumano e evocam no leitor (e no estudante) um sentimento perturbante e progressivo de violação mais ou menos... sadomasoquista e necrofílico. Sem menosprezo, claro, pelo valor singular e precioso da curiosidade científica, da modesta e sistemática pesquisa dos mecanismos das doenças. Mas como não rejeitar as tentativas de redução das experiências de sofrimento - a dolência e a doença -, das angústias existenciais e até das tragédias colectivas e familiares, a eventos químicos e eléctricos de certas vias neuronais, a processos atomísticos e algoritmos computacionais, sem os quais, bem entendido, não se teriam produzido nem existiriam, mas que acabam por não explicar sequer a função vital da dor, os aspectos globais e emocionais da conservação da integridade e da individualidade do organismo?

Iremos nesta breve nota sugerir que uma obra recentemente traduzida pela primeira vez em língua viva, a Arquipatologia (Archipathologia in qua internarum capitis affectionum essentia, causae, signa, praesagia, \& curatio acuratissima indagine edisseruntur) de Filipe Montalto ou de Montalto, publicada em Paris em $1614^{3}$ é a primeira naturalização da dor, especialmente bem legível nos extraordinários e fundacionais capítulos dedicados à dor. A este propósito contribuiremos, muito pontualmente, para a discussão acerca da natureza da dor enquanto experiência: falaremos de dor-dolência e, muito sumariamente, de mecanismos conhecidos da dor, focados na componente emocional e não na perceptiva. ${ }^{4}$

3 Filipe Montalto, Arquipatologia, na qual são detalhadas, em muito cuidadosa investigação, a essência, as causas, os sinais, os presságios e a cura das afecções internas da cabeça (trad. Domingos Lucas Dias, Inês de Ornelas e Castro, Joana Mestre Costa), Lisboa, Colibri, 2017.

4 Consideremos, perdoe-se a grosseira simplificação, quatro classes gerais de dor que correspondem a diversos "mecanismos" de transmissão e processamento de "sinais": a dor nociceptiva propriamente dita (resposta transitória a uma lesão ou estímulo nocivo, em geral cutâneo - a pele é o maior órgão do corpo e a principal fronteira com o mundo exterior), mas também osteoarticular, e muscular, estas as dores globalmente mais 
Se no plano da quantidade a dor vai da analgesia (quando congénita associada a múltiplas e graves complicações ${ }^{5}$ ) e do incómodo prurido e titilação das pequenas percepções leibnizianas tal a inquietude dos sentimentos confusos "que ne diffère de la douleur que comme le petit diffère du grand, qui fait pourtant souvent notre désir et même notre plaisir, en lui donnant comme un sel qui pique [...]"6. Conjecturamos que este modelo da sensualidade como terreno de aguilhões ou espinhos do desejo replicando o emblema célebre da consciência fixado por Cesare Ripa na sua Iconologia - tenha deslocado a "sede" da dor do espaço fronteiriço do tacto para o espaço interior da apetição - emparceirada com o seu contrário, a volúpia. No plano da qualidade a situação é bem mais complexa. W. Wundt, o filósofo e o criador da psicologia experimental, no âmbito da sua teoria tridimensional das emoções, apoiava Kant quando dizia que a experiência de dor devia preceder cada estado de prazer, assim como cada obscuridade suspende cada sensação de luminosidade. ${ }^{7}$ Pense-se nas diferenças entre a dor nua, tipo picada de alfinete (sem sentido acrescentado, "reflexa" instintiva, sem requisito representacional superior), a dor visceral, como a

prevalentes; a dor inflamatória nociceptiva; a tenebrosa dor neuropática é análoga, mas originada no tecido/sistema nervoso; a dor funcional resultante da hipersensibilidade à dor. Prevalece hoje a explicação fisiológica da "teoria do portal" de Melzack e Hall (O desafio da dor, Lisboa, FCG, 1987), dos circuitos reaferentes, das polissinapses e transmissores químicos capazes de inibição e modulação central, centrífuga, dos influxos "álgicos". Em cada situação diversos mecanismos fisiológicos poderão estar envolvidos.

5 Analgesia congénita associada por vezes a anedonia, apatia ou ataraxia.

6 Leibniz, Novos Ensaios, (Lisboa Colibri, trad A. Cardoso, p. 112: “a natureza nos deu o acicate do desejo, sob a forma de rudimentos ou elementos da dor, ou, por assim dizer, semi-dores ou (se quereis falar abusivamente a fim de que a expressão seja mais vigorosa) pequenas dores imperceptiveis, a fim de que gozássemos dos atractivos do mal sem sofrer o incómodo respectivo (...)".

7 As três dimensões das emoções referidas eram: prazer/dor, excitação/depressão e tensão/distensão. Wundt, Introduction to Psychology, N.York, MacMillan, 1919 (2nd ed., transl. R. Pinter), I, p. 557. O tono - da homeostase - do sentimento ligar-se-á aos efeitos da dissonância, aos do "white noise", à discriminação figura-fundo, pergunta Wundt, que se inclinava para que a dor fosse um elemento de base da sensibilidade, ou do processamento geral - amodal, polimodal ? - das informações sensoriais: o que se sabe hoje das endorfinas e dos opióides e análogos suporta a noção da base visceral-sensorial, humoral, dos sentires (feelings), a tonalidade, a coloratura, a têmpera qual regime de "fé animal" da consciência Como para a dor, há contrariedade (não a polaridade) entre subjectividade (dos sentires e sentimentos sensoriais) e os determinantes objectivos das sensações que não podem ser primários, absolutos (Wundt, Ibid., vol. 1, p. 430 e vol. 2, pp. 553f). 
dor reflexa do enfarte do miocárdio, a dor do membro fantasma ${ }^{8}$ ou a dor total do cancro avançado sub ou mal-medicado. Fenómeno irrevogável, inobjectivo, intransitivo, imediato, bem ao contrário da percepção comum, a dor - designadamente no ser humano - , aguda ou crónica, é incorrigível (num sentido óbvio) e, em geral, localizável e não anónima, substantiva ${ }^{9} \mathrm{e}$ insubstituível (excepto, como reza o aforismo, por dor mais intensa ${ }^{10}$ ), em oposição à "corrente da consciência" que engendra, incorpora e excretam sucessivos conteúdos e imagens evanescentes inscritos em textos, subtextos e contextos os mais variáveis. Sem prejuízo de que, em cada espécie e, inclusive, transversalmente, em géneros e famílias animais, a expressão fisiognómica e corporal assume um cunho biológico imperativo e absoluto; vale aquém da esfera da evidência e pré-constitui-se fora da subjectividade? Pense-se nos mecanismos neurovegetativos emocionais e na feição singular do pensamento de lactentes e de crianças na primeira infância e na ulterior multiplicidade da expressão verbal da dor (muito para lá dos gritos de susto, medo, alarme, terror, ameaça de predador, etc.), aquém da descrição fina "na terceira pessoa", seja a da clínica seja a da tragédia...

\section{Filipe Montalto e a sua Arquipatologia}

$\mathrm{O}$ adoecer sucedia por quatro modos principais: (i) doenças dos humores, (ii) das partes similares, (iii) dos órgãos ou partes instrumentais, e (iv) soluções de continuidade (rupturas, lacerações) de todo o corpo

8 Trata-se de uma síndrome complexa e conhecida que levantou muitas dúvidas e interpretações. A sua descrição por Ambroise Paré em 1552 transmite uma sensação de medo e mistério e também Descartes mencionou um caso, e já no século XIX Magendie descreveu outros casos. O termo "phantom limb" foi cunhado por Weir Mitchell para descrever a sensação persistente do membro ausente como consequência quase invariável de amputação. O seu estudo de 90 amputados da Guerra Civil Americana foi publicado em 1871. Mostrou que em muitos casos eram dolorosos e que era extremamente difícil o seu tratamento ter sucesso. Há pelo menos três fenómenos distintos: "sensações fantasma" que afectam o esquema corporal, dores no membro fantasma e dores no coto - o último sendo uma forma de dor neuropática. Para Merleau-Ponty, a anosognosia e o membro fantasma não admitem nem uma explicação fisiológica nem uma explicação psicológica.

9 Acerca do carácter irredutível, "material”, insubstituível e substantivo da dor, e não adverbial ou adjectivo (como na mentira torpe sistemática ou da náusea emetizante que suscita ou, noutro registo e mais polemicamente, na "perda do objecto")

10 Recordar o Aforismo de Hipócrates (II, 48): se ocorrem duas dores simultâneas em locais diferentes, a mais intensa apaga a menos. Estranha noção, que sugere a de humanidade ferida... e, a uma escala incomparável, a de banalidade do mal (as primeiras atingem o nosso país político, famélico de Verdade, de Direito $e$ de Justiça). 
ou de alguma das suas partes. A doença recaía assim sobre as "coisas naturais" (elementos, humores, espíritos, faculdades), não podendo haver doença propriamente dita fora do corpo, seja no meio exterior, seja na alma. Havia ainda as "coisas não naturais", não pertencentes à natureza nem contra ela, e eram agrupadas em seis géneros: ar e ambiente, comida e bebida, trabalho e descanso, sono e vigília, deplecção e replecção (ou excreções e secreções) e movimentos ou afectos da alma. Os fenómenos psíquicos, afectos da alma, eram considerados exteriores aos humores, partes e funções que no homem podiam caducar, enfraquecer e falhar - a sua natureza somática, sendo o lugar correspondente ou idêntico ao do meio ambiente, a grande causa externa da enfermidade, fonte de males, miasmas e noxas com repercussão no corpo, nos seus quatro humores (sangue, pneuma, bílis amarela e bílis negra). Daí a conhecida fórmula "As faculdades da alma seguem os temperamentos do corpo" e a não consideração de uma etiologia (e patogenia) propriamente mental; por isso a terapêutica "psíquica" galénica destinava-se a manter o bom ânimo do paciente e a ganhar a sua confiança, como nos ensinava Garcia Ballester ${ }^{11}$. Para ajudar os "movimentos do ânimo" utilizavam-se medicamentos, bebidas, meios físicos, música e mais raramente as palavras.

A vigência do galenismo está bem presente na obra montaltiana, mas é surpreendente o lugar e a importância que concede à dor, embora se possa encontrar menção à dor a partir do período renascentista, por exemplo em Jean Fernel e Felix Plater, e, mais tarde em Thomas Willis. Willis, que tal como Descartes procura dar bases materiais à sensação e ao movimento, introduz uma dimensão química, o modelo do cérebro como alambique pingue e do reflexo nervoso como ignição $e$ "implosão" mental (o que o autor do póstumo Traité de l'Homme recusava). Montalto inicia a Arquipatologia por uma análise muito subtil da dor, detalhada e alongada, o que nos surpreende pela importância raríssima que o autor the atribui. A dor é considerada uma paixão do apetite, não do sentido externo, nem da faculdade interna proveniente da faculdade imaginativa, mas da tristeza do apetite sensitivo, dando, portanto, realce ao componente afectivo das algias e dolências. A causa imediata e contínua da dor é uma afecção preternatural e violenta levando o corpo do estado natural ao inatural. Mas é no Tratado Segundo (Dor de Cabeça) que vai debruçar-se detalhadamente sobre cefalalgia, cefaleia e hemicrania, expor o tratamento da dor em geral, e mostrar um fino conhecimento clínico e um desenvolvimento para lá

11 Garcia Ballester, L. (1972), Alma y enfermedad en la obra de Galeno, Universidad Valencia - Granada. 
da matriz hipocrático-galénica que é a sua, e do seu tempo. No capítulo II, depois de caracterizar as diferenças da cefalalgia nas partes afectadas, fora do crânio ou dentro do crânio, considerando que a substância do cérebro não dói, o que reveste o cérebro é que causa dor, faz uma curiosa referencia ao possível erro de tradução duma edição de um livro de Galeno, onde se lê sobre a origem da cefalalgia: "ou da pele ou até do próprio cérebro" devendo traduzir-se segundo Montalto por "ou da pele da própria cabeça". ${ }^{12}$ Insiste na diversidade das causas, onde além da intemperança, cacoquimia, pletora, obstrução dos vasos, espírito flatulento, afecção inflamatória, de inspiração humoralista, menciona a sífilis, referindo dores atrocíssimas, provenientes da cacoquimia, "mas sobretudo de uma indizivel qualidade deletéria", provável constatação das dores fulgurantes que a sífilis podia causar (Capítulo III). Distingue idiopatia, afecção própria, da simpatia, relação de reciprocidade entre diferentes partes do corpo capazes de se influenciar e afectar mutuamente. Ora a cabeça sofre com todo o corpo ou com um membro particular, sendo que o cérebro sofre com o estômago, útero, fígado, baço, rins, extremidades, partes do dorso, hipocôndrio, diafragma, e nas mulheres, o pulmão e as mamas. Mas, mais do que todos, "arrastam a cabeça para a simpatia sobretudo o estômago e o útero" (Capítulo VII). Menciona os tipos clássicos de dor, pungitiva, tensiva, gravativa e pulsativa, que mostram a especificidade (anatómica) da punção, da tensão, do peso e da pulsação (Galeno), e dá relevo às características da própria pessoa, escrevendo que "o despertar da dor por motivo negligenciável indicia fraqueza da cabeça", associada a imperfeição ou lesão dos sentidos externos ou das funções principais e também que a aptidão para sofrer por causa pouca revela a exuberância dos sentidos (Capítulo X). Outra nota importante é a noção da ligação às doenças sistémicas, falando das "cefalalgias por consenso", que acontece nas febres do corpo todo, acompanha os paroxismos das febres e desaparece com o seu desaparecimento; mas se desaparecendo ou tornandose intermitente a febre, a cefalalgia se mantém, se aumenta, aumentando aquela, o sofrimento é misto de propriedade e de consenso (Capítulo XII). Montalto não esquece as causas directas, como os traumatismos cranianos, vermes, tumores e infecções. A dor de cabeça intensa e contínua, com febre, é muito perigosa por indicar inflamação interna ou afecção semelhante, e esta, veemente; mas se há-de terminar-se em salvação ou em morte, perceber-se-á pelos outros indícios (Capítulo XIII).

12 Levantando assim a questão das erradas interpretações dos escritos de Galeno por traduções mal formuladas. 
No tratamento da dor em geral (Capítulo XIV) o autor começa dizendo que na dor concorrem três factores: a causa dolorifica, a sua percepção e o mal-estar dai nascido. Assim usam-se três espécies de remédios: os que destroem a causa, os que se opõem ao mal-estar e os que contrariam a sensibilidade produzindo entorpecimento. A primeira era a via justa uma vez que acompanha a doença como a sombra acompanha o corpo, a segunda alivia-se a dor com os medicamentos anódinos e podem ser inúmeros alimentos, decocções ou óleos que enumera, mas se a dor for muito intensa é necessário recorrer aos remédios que produzem entorpecimento, chamados narcóticos. Parece notável o balanço que procura fazer quanto à sua utilização, "não recorra a eles mais depressa do que convém, nem os evite completamente ou os remeta para lá do limite". Equaciona, inclusivamente, a escalada de opióides Enumera nas cefalalgias por pletora ou na biliosa e pituitosa, os meios para alterar ou evacuar os humores, como a flebotomia, a sangria, a purga, o regime de vida, clisteres, supositórios, fricções, ligaduras e ventosas, banhos, etc.

Montalto é sistemático, pois escreve acerca das três faculdades:

A primeira é o sentido externo que, na medida em que é sensivel, reconhece o movimento proveniente do objecto. Logo depois, a faculdade interna, espécie elementar, é certo, da faculdade imaginativa ou da estimativa, coextensa aos órgãos, percebe a mesma mudança causada pelo objecto como inconveniente e contrária à natureza, o que, aliás, se irá esclarecer. A tristeza do apetite sensitivo segue-se imediata e necessariamente do mal presente. Ora, que a dor exija previamente essa elementar acção da faculdade imaginativa ou estimativa, deduz-se do facto de o objecto bom ou mau do apetite sensitivo ser previamente conhecido. Mas o conhecimento não pertence ao apetite. ${ }^{13}$

A teoria montaltiana é efectivamente sistémica, hierarquizante, com efeitos práticos a vários níveis e em múltiplas situações patológicas. $\mathrm{Na}$ terapêutica da frenite, por exemplo, “(...) só há uso proveitoso (opportunus) dos medicamentos locais quando se atende ao corpo todo; pela sangria, se o excesso (multitudo) atormentar; pela purga, se a cacoquimia atacar; mas, pelo menos, o uso de repulsores deve estar presente desde o início." ${ }^{14}$ A concepção da tristeza do apetite gerada pela dor, simultaneamente tonalidade emocional, "estado motívico" (no idioma musical) e "humor

13 Montalto, cit., p. 42. Faculdade imaginativa (imaginatrix) ou estimativa (aestimatrix), coextensa aos órgãos cerebrais cognitivos. Distinguir e decidir qual dos objectos sensíveis, este sem dano, aquele com dano, afecta o sensório, é próprio de uma faculdade superior. De salientar que a dor é e/ou produz uma afecção contrária à natureza.

14 Ibid., p. 178. 
epistémico" retira a tristitia da lista dos pecados mortais e da demonologia da acídia do meio-dia e significará, pensamos, a pré-determinação da "tabula rasa" da psique por notações como a das tablaturas (que inspiraram os modelos leibnizianos da mente).

\section{Do objecto e significado da dor}

Montalto fala-nos de medicina galénica. Todavia determinou a experiência de dor e suas propriedades de modo não-galénico. Como distingue malestitia, tristeza, aflição, sofrimento da dor que sempre acompanham? Condicionado pela aforística médica hipocrática, Filipe Montalto neutraliza a (voz da) primeira pessoa, recorrendo a um operador que evoca a necessidade, a defesa, a urgência, a repetição, a desmesura, a interioridade, o destempero de uma ordem funcional típica, universal - a dor -, a saber, um afecto, uma apetição (oretikon, órexis, thumus, epitímia). ${ }^{15}$ Teve o mérito de excluir o doer, a dolência, o sofrimento do âmbito do erro, do pecado, do mal, do absurdo, inscrevendo-os no "cérebro emocional" com filamentos da sensação, nomeadamente táctil: “(...) a depravação da função é a mudança da mesma noutra espécie, como será na sensitiva, na medida em que ela, ao julgar sobre o objecto, se ilude, considerando-o diferente do que é; tal ocorre na apetitiva, na medida em que tem propensão para o estranho, como a concha, a cal ou a cinza, tal como acontece na pica. $\mathrm{Na}$ dor, pelo contrário, o objecto é apreendido exactamente tal como se apresenta e como deve ser percebido por um órgão temperado." (Montalto: $65)$.

Que objecto é esse? Um objecto externo? O agente mecânico que fere e lacera? O som que agride? A luz que cega? A marca ou o sinal internalizado desse objecto?

A resposta a esta interrogação passou pela teorização das sensibilidades proprioceptiva e interoceptiva e pela tematização do conceito de cenestesia em finais do século XVIII. Jean Starobinski ${ }^{16}$ e, mais recentemente, D. Heller-Roazen, (The Inner Touch, 2009) traçam

15 Acerca da actualidade da concepção afectiva da dor vd. Melzack e Wall, 1982/1987: 208s. "O apetite (oretikon) é a faculdade da alma que procura alimento (Aristóteles, Sobre a Alma, 413b6; 414a30-34). Abarca as três funções do desejo (epithymia), espírito, e vontade (ibid.: 414b) e é, em conjunção com a sensação (aisthesis) e a intelecção (noesis) a causa suprema do movimento da alma." (ibid.: 414b).

16 Starobinski, J. (1990), “A short history of bodily sensation”. Psychological Medicine, 20, pp. 23-33. 
a evolução da ideia sob diferentes nomes, seguindo as suas vicissitudes até à década de 1930. A palavra remonta a 1794, numa tese em Halle, de Hubner, mas parecem ser de Johann C. Reil as ideias expostas. O espírito, o mundo exterior, o próprio corpo, constituem três campos distintos, cada um acessível de um modo perceptivo específico. A cenestesia é a informação sensível que emana do corpo por via nervosa. É com Ribot em França que se vai alargar a noção a todo o campo da psicopatologia, tornando-a em modelo explicativo para um conjunto de afecções: despersonalização, dupla personalidade, depressão e exaltação da personalidade, dissolução do eu. A autoridade de Ribot era imensa e todos os psiquiatras franceses passaram a recorrer a ele para definir a cenestesia. Em psiquiatria, no prolongamento das ideias de Ribot, Séglas (1895) ${ }^{17}$ atribuiu papel importante aos transtornos cenestésicos, com responsabilidade principal nos estados de despersonalização e nos delírios de negação melancólicos (síndrome de Cotard). Mais tarde, Dupré ${ }^{18}$ cria o termo cenestopatia para designar um desequilíbrio particular da cenestesia, da sensibilidade comum ou interna. São alterações locais da sensibilidade, irredutíveis a um outro processo mórbido, localizadas e circunscritas a um certo território. Havia dois tipos principais de cenestopatias, um com dores, outro com parestesias. Não se tratava de doença afectiva, mas somente de uma alteração da tonalidade normal da sensibilidade física de certos territórios orgânicos. Por ordem de frequência atingia a cabeça, o abdómen, o tórax e por fim os membros. As associações mórbidas mais comuns das cenestopatias são as algias, sob a forma de nevralgias, migraines (enxaquecas), mialgias e outras dores. Para Dupré, trata-se de um desequilíbrio constitucional da sensibilidade, sendo as algias e cenestopatias dois síndromes da mesma família, com prognostico em geral desfavorável $\mathrm{O}$ conceito cenestesia é actualmente menos usado e em França foi substituído pela designação mais abstracta de "esquema corporal". O tema da imagem corporal desenvolve-se depois pela influência da psicanálise e das abordagens fenomenológicas do corpo, nomeadamente em Merleau-Ponty ${ }^{19}$. Em La conscience morbide Charles Blondel ${ }^{20}$ desenvolve um modelo explicativo para a origem dos delírios baseando-se na ideia de um estado pré-delirante como expressão de uma forma altamente personalizada de cenestesia visceral. Ele considera que

17 Séglas, J. (1895), Leçons cliniques sur les maladies mentales et nerveuses. Paris: Asselin et Houzeau.

18 Dupré, E. (1925), Pathologie de L'Imagination et de L'Émotivité. Paris: Payot.

19 Merleau-Ponty, M. (1957), Fenomenologia de la Percepcion. México: Fondo de Cultura Económica.

20 Blondel, Ch. (1928), La Conscience Morbide. Paris: Félix Alcan. 
uma consciência é mórbida depois de a decantação cenestésica ter cessado de se produzir, aderindo às formações da consciência clara componentes inabituais, anormalmente irredutíveis. A sua presença em todos os momentos da vida psíquica, a sua irredutibilidade e a consciência inteiramente mórbida é lugar de uma alteração global, modificando e interferindo na organização conceptual que a colectividade, a inteligência e a linguagem adaptaram às condições objectivas da nossa existência, entre os homens e as coisas. Foi a total dissolução do objecto externo da dor: é um dado adquirido que ao contrário do ver e do palpar a sensibilidade álgica não conhece, não descreve, objectidades, não recebe, não percebe "dados dos sentidos" mas não deixa de ser produtora de qualia ou qualidades altamente variadas, complexas, localizáveis - mais facilmente no sistema locomotor que no visceral -, estruturadas e específicas.

Dir-se-á da dor o que se diz da emoção: serve para aumentar a fitness darwiniana das espécies que a experimentam. O seu significado biológico mais imediato é activo, reactivo: a reacção a um perigo, a uma agressão, a uma noxa, demonstrável em formas primitivas de organismo. A dor é uma condição de possibilidade da mente, ou esta mesma em embrião: "A vast number, perhaps the vast majority, of life forms cannot be shown unequivocally to possess mind. But none the less (...) while they 'seek' and prolong contact with some items of their surround, e.g. food, they 'avoid' or break off contact with other items, which would harm them. Thus with the reflex action of the brainless frog (...)." ${ }^{21}$ Reflexos protectores inatos, modulares (automáticos, encapsulados, não conscientes) e eventualmente nociceptivos; nos vertebrados, pelo menos, estão dependentes de órgãos nociceptores especializados, em número incontável na superfície do corpo, mas também nas "fronteiras" viscerais internas. Daqui que a contribuição dos mecanismos da dor/dolência para a determinação dos limites da psicologia computacional possa vir a ser muito importante.

\section{Perplexidades filosóficas e experiências literatas}

Consideramos que os limites da "computational psychology" se testam pela possibilidade de processos e conteúdos psíquicos robustos dispensarem a mediação representacional e possuírem propriedades semânticas e referenciais, instalando-se per se, imediata e automaticamente, na ordem da consciência e da autoafecção, demarcando-se ao mesmo

21 Sir Charles Sherrington, On Human Nature, Penguin, 1940/1955: 233. 
tempo dos modos intensionalistas, proposicionais e fenomenológicos de inteligibilidade da cognição e da crença. É crível que as tão heterogéneas e clinicamente distintas, dor nua e dor fantasma, dor aguda e dor crónica, por exemplo, possam partilhar os mesmos traços distintivos clássicos:

- Unidade Corpo-mente

- Deslocalização

- Desproporção

- Regime de repetição sem fim

- Repulsão, aversão

- Suscita compaixão, sentimento de afiliação, horror

Esta uma excelente lição de Jerôme Porée..$^{22}$ Medo, desespero, culpa, dor moral são outras constelações associadas. Mas os traços major da dor/ dolência, (i) imediatidade e incorrigibilidade, a dor como auto-referência, notícia de si (index sui) e (ii) a transparência e expressividade fenomenal, a notícia vera (index veri) são, nos planos epistémico e biomédico, traços mais fundamentais (deixemos de lado o contra-argumento de decepção sistemática por modulação e processamento central da dor e os casoslimite da "ferida que dói e não se sente", da agnosia e assimbolia da dor por via patológica ou cirúrgica (pré-frontal, cingulum anterior).

Afirmam alguns historiadores que o processo de naturalização das paixões ficou estabelecido com a magna obra de Burton, na sua famosa The Anatomy of Melancholy, e a naturalização das doenças mentais com as de Jerome $\mathrm{Gaub}^{23}$; apesar de eminentes estudiosos o terem esquecido ou ignorado, como Jean Starobinski, Roselyne Rey e Roy Porter, atrevemo-nos a sugerir que a naturalização da dor ficou instituída com a Arquipatologia.

22 Jérome Porée, "La sensation douloureuse existe-t-elle ? Neurophysiologie, psychologie et phénoménologie" in Maria José Cantista, Ed., A dor e o sofrimento, 2001, Porto, pp. 103-124.

23 Jerome Gaub (Hyeronimus Gaubius, 1705-1780), em Instituitiones Pathologiae Medicinalis e em De Regimen Mentis (ed. de Rather,1965: x, 16) estabelece a patologia médica neometodista e rejeita a noção do homem-máquina propondo uma "medicina psicossomática"; a sua doutrina apoia-se na força dos fluidos elásticos (ib., p. 146) e das fibras do corpo que causarão nos estados orgânicos humorais a uma oscilação entre estados de espessamento (spissitudo) e adelgaçamento (tenuitas) (sic), buscando o equilíbrio (p. 58) e, na doença, suscitam a reativação das defesas (molimina, ib., p. 164, 169) e a recuperação das forças (in L. J. Rather, Mind and Body in Eighteen Century Medicine. London, Wellcome Historical Medical Library. 1965; também M. S. Marques, "Força, debilidade e (i)numeracia em Observações Clínicas de José Pinto de Azeredo", 2017- para publicação). 
Como dissemos, Montalto enfraquece a divisão tripartida das faculdades do galenismo e da medicina escolástica - alma concupiscível, irascível, racional - abrindo o caminho a um certo ecletismo que frutificou com a ciência dos modernos. A sua doutrina resume-se numa analogia simples: "nas paixões da alma (animi pathematibus), o prazer e a própria dor não são a estimação (aestimatio) ou a compreensão do bem ou do mal, mas a afecção concupiscível consequente a esses conhecimentos, ou uma afecção da vontade. Assim, pois, se há-de pensar também em relação às enfermidades do corpo (corporis pathematibus), porque não é a própria sensação que cria o prazer ou a dor, mas a afecção resultante das funções de outra faculdade.". Com ela veio o reconhecimento da realidade clínica da dolor animi, ${ }^{24}$ das infindas dores sem nome que tem sido sempre a vida da maioria dos povos. Enfim, a tristeza do apetite é tristeza epistémica da faculdade hegemónica - é desvio, elisão, dos descriptores rígidos da referência (para irmos direitos ao nome-que-recebe e à escala da deixis que Fernando Gil caracterizou no seu Tratado da Evidência)?

Alguns filósofos têm, investigado apuradamente o que designam por paradoxos da dor, um dos quais é uma espécie de indizibilidade invisível ao senso comum, mas anódina para o funcionamento quotidiano de animais canoros e/ou "vociferantes": "in a case in which a reference has been stipulatively assigned to a concept, it is generally possible to establish a practice of using the concept by setting one's sights on accepting true propositions containing the concept and rejecting false ones. Without inconvenience for everyday life (...)" ${ }^{25} \mathrm{E}$ o autor expressamente recorre à filosofia da ciência como paradigma, frisando que, aceitar as proposições que contêm conceitos verdadeiros e rejeitar as que contêm falsos conceitos é a maneira de prefigurar, configurar e refigurar pelo uso, em discursos científicos, conceitos teóricos. Apenas três comentários. (i) julgamos que a teoria de Kuhn - exemplo, a estabilidade e incomensurabilidade do galenismo -, enfraquecem a proposta de C. Hill; (ii) a noção vigente de corrente da consciência implicará, como disse William James, a precariedade e substituibilidade de perceptos e conteúdos vivenciais e a deposição da identidade (das tablaturas e partituras sensoriais à auto-

24 Montalto, op. cit., pp 42, 44: dolor animi, na terminologia de Montalto: “(...) para distinguir a dor do corpo da dor da alma (animi). Na dor da alma, pela qual nos relacionamos com os irracionais, há, como matéria, a estimação do mal presente; na intelectual, específica nossa, há também a compreensão do mal presente.”.

25 Christopher Hill, The paradox of pain: in M. Aydede, ed., Pain. New essays on its nature and the methodology of its study. Cambridge, Mass., MIT, 2005, pp. 75-88 (p. 93). 
afecção, ao Si e ao sujeito) num espaço-serial de invariantes relacionais, rapsódicos, portadores de múltiplos conteúdos, desde o "azul marinho" (que vejo ou imagino) ao sentido das locuções "e", "portanto", etc., acompanhados dos respectivos e inerentes modos ou sentires?; (iii) os marcadores somáticos endógenos das emoções e afectos (segundo António Damásio) e os, antes mencionados, modos de pensamento do pequeno infans com a sua espantosa multiplicidade da expressão da dor e do prazer, muito para lá do grito, do riso e do choro, e das formas pré- e para-verbais, não conferem um estatuto ontológico não computacional à dor/dolência? Estas interrogações evocam o multiiverso de Tlön (das Ficções de Jorge Luís Borges): um "mundo [... como... ] série heterogénea de actos independentes. É sucessivo e temporal, não espacial. Não há substantivos [nem objectos] na conjectural Tlön [...] há verbos impessoais [...isto...] no hemisfério austral [...]. Nos [idiomas] do hemisfério boreal [...] a célula primordial não é o verbo, mas o adjectivo monossilábico. Não se diz lua: diz-se aéreo-claro sobre escuro-redondo ou celeste alaranjado-ténue ou qualquer outra combinação [... abundam] os objectos ideais, convocados ou dissolvidos, conforme as necessidades poéticas. Determina-os às vezes a mera simultaneidade: Há objectos compostos de dois termos, um de carácter visual outro auditivo: a cor do nascente e o remoto grito de uma ave. Há-os de muitos termos: o sol e a água contra o peito do nadador, o vago rosa trémulo que se vê com os olhos fechados, a sensação de quem se deixa levar por um rio e também por um sonho. (...)". ${ }^{26}$

A pergunta é: como será a dor a Norte? E a Sul? Quando alguém sofre, grita, chora, estaremos no Norte ou no Sul?; em Tlön um habitante do Norte sente, compreende, empatiza com uma emoção ou sentimento de um habitante do Sul? Sofre, goza, tem as "mesmas" dores, prazeres, esperanças, angústias e expectativas? Como poderão as suas gramáticas e semânticas ser co-referentes? São comparáveis, partilháveis, as perspectivas, ideias e experiências?

Finalmente, há temas clássicos da filosofia que se fazem convidados. Descartes, Swift, Buffon, mecanicistas, recusam real interioridade, animação e padecimento aos animais, Gassendi, La Fontaine, os materialistas, Rousseau não os reduzem a máquinas. ${ }^{27}$ Bayle e Willis terão uma posição intermédia. ${ }^{28}$ Mas são Leibniz e Locke que se opõem

26 Jorge Luís Borges, Ficções, in Obras, 1989/1998, pp. 451-552.

27 R. Rey, Histoire de la douleur, Paris, La Découverte, 2000 (1993), pp. 78. 107, 453, 495 passim.

28 Ibid., p. 424. 
mais veementemente à igualdade por baixo de bruta, insanes e crianças (e mulheres). Roseline Rey adverte que Leibniz, depois da correspondência com Bayle, vai em Commentatio de anima brutorum (1710) defender a alma dos animais e a sua passibilidade (a forma substancial) "(...) d'une manière que les rendit [aux formes substantielles] intelligibles [...], leur nature consiste dans la force et que de cela s'ensuit quelque chose d'analogique au sentiment et à l'appétit (...)"29. Gilles Deleuze, célebre leibniziano, explana: “(...) l'âme se donne une douleur qui porte à sa conscience une série de petites perceptions [...] enfouis dans son fond. [...] le fuscum subnigrum hante Leibniz: les substances où les âmes tirent de leur propre fond (...)". ${ }^{30}$

Acerca da dor, da dolência e do sofrimento, do dó, da condolência, da pietà, a arte e a literatura oferecem, evidentemente, tesouros sublimes para a reflexão em imagens, metáforas, conceitos e narrativas múltiplas: desde Os Thibault ao Ivan Illich e a passos do Diário de Miguel Torga; todavia, nem as formas mais apuradas da poética e da mística, como as de Simone Weil, parecem ser as que mais nos convêm para re-equacionar os paradoxos da dor. Os modos e filosofemas de Kierkegaard e de Maria Zambrano são porventura mais propícios. E, da medicina reflexiva recente, não podemos omitir autores como Eric Cassel (Suffering and the Art of Medicine) ou Dick Zaner (múltiplos títulos). Hoje multiplicamse as iniciativas académicas no âmbito das Humanidades Médicas (dita Medicina Narrativa) e pugna-se por reforçar, como primeira regra da Arte, a escuta autêntica da voz do doente - para lá da anamnese e da história bem feitas - , e modo de subtrair a clínica à captura pela Gestão e Contas (profissões outras!). Assim as primordiais categorias a que se deveria deitar a mão são as expressões primeiras do doente: a dolência, a dor, o grito, o mal-estar, o pathos e as experiências que os caracterizam e/ou lhes subjazem (na terminologia médica, as queixas, os sintomas, a configuração sindromática, o stress, a tristeza, o desespero, a depressão...). Esta foi, crêmos, também a lição de Montalto.

29 Leibniz, NE, cité par R. Rey, ib., p. 96n, 20.

30 E prossegue: "C'est le deuxième aspect du maniérisme, sans lequel le premier resterait vide. Le premier c'est la spontanéité des manières qui s'oppose à l'essentialité de l'attribut. Le second c'est l'omniprésence du sombre fond qui s'oppose à la clarté de la forme" - Deleuze, Le Pli, Paris, Minuit,1988, cit., p. $76 f$. 


\title{
RESUMO
}

Os autores fazem uma leitura dos notáveis Livros sobre a dor da Arquipatologia de Filipe Montalto (1614). Interpretam-nos como a primeira naturalização e simultaneamente a defesa consequente de uma teoria emocional da dor e da dolência. Abordam depois sucintamente aspectos da atitude reducionista sobre a dor e suas eventuais implicações sobre questões do conteúdo, da referência e da "psicologia computacional".

Palavras-chave: dor - Montalto - Arquipatologia - qualia - emoção.

\begin{abstract}
The authors make a reading of the remarkable books on pain of the Arquipatologia of Filipe Montalto (1614). They interpret this work as the first naturalization and simultaneously the consequent defense of an emotional theory of pain and illness. They then briefly discuss aspects of the reductionist attitude about pain, and its implications on matters of mental content, reference and "computational psychology".
\end{abstract}

Keywords: pain - Montalto - Arquipatologia - qualia - emotion. 
EDITORIAL

ARTIGOS

AT THE HEART OF A DECISION IS A NARRATIVE

R. M. Zaner

AGONIA E RAZÕES PARA AGIR: UMA CRÍTICA A PARFIT

Pedro Galvão

A PROPÓSITO DA NATURALIZAÇÃO DA DOR NA OBRA DE FILIPE MONTALTO

Manuel Silvério Marques e José Morgado Pereira

AS MEDITAÇÕES SOBRE AS LÁGRIMAS E O CHORO DE JOHAN FRIEDRICH SCHREIBER

Palmira Fontes da Costa

REDESCOBRIR A SAÚDE QUE NUNCA SE PERDEU. DOENÇA, SOFRIMENTO E CURA NO BUDISMO

Paulo Borges

COMPREENDER A DOR. A PROPÓSITO DE UM CASO DE ANOREXIA NERVOSA CRÓNICA

Dulce Bouça

O PASSO DO ABISMO: O DESVIVER, A AGONIA E A MORTE DIGNA

Manuel Silvério Marques

A “BOA MORTE” DE BACON

António Lourenço Marques

SEDAÇÃO PALIATIVA, PERSPETIVA DE UM CLÍNICO

Madalena Feio

ENSAIOS

LA RESPUESTA AL PROBLEMA DEL NO-SER EN LA METAFÍSICA DE ARISTÓTELES

Maria Carmen Segura Peraita

GRAMSCI E I QUADERNI: FILOSOFIA DELLA PRASSI E IMMANENZA TRA MATERIALISMO E IDEALISMO

Luca Onesti

PRÉMIO PROF. DOUTOR JOAQUIM CERQUEIRA GONÇALVES PARA ALUNOS

DO 1. ${ }^{\circ}$ CICLO/ CURSOS DE LICENCIATURA (Edição de 2018)

KANT NO JARDIM DO NÃO SEI QUÊ. NOTAS AO PARÁGRAFO §49

DA CRÍTICA DA FACULDADE DO JUÍZO

João Maria Carvalho

DISSERTAÇÕES

LUDO-ESTÉTICA

Pedro Miguel Celestino Pereira

RECENSÕES

THOMAS P. KASULIS, ENGAGING JAPANESE PHILOSOPHY:

A SHORT HISTORY, HONOLULU, UNIVERSITY OF HAWAI'I PRESS, 2018

Ricardo Santos Alexandre

INSTRUÇÕES AOS AUTORES - NORMAS DE PUBLICAÇÃO

INSTRUCTIONS TO AUTHORS - PUBLICATION PROCEDURES

*

\section{Patrocínios}

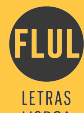

LISBOA

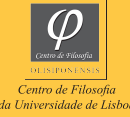

FCT 